O menos que é mais em

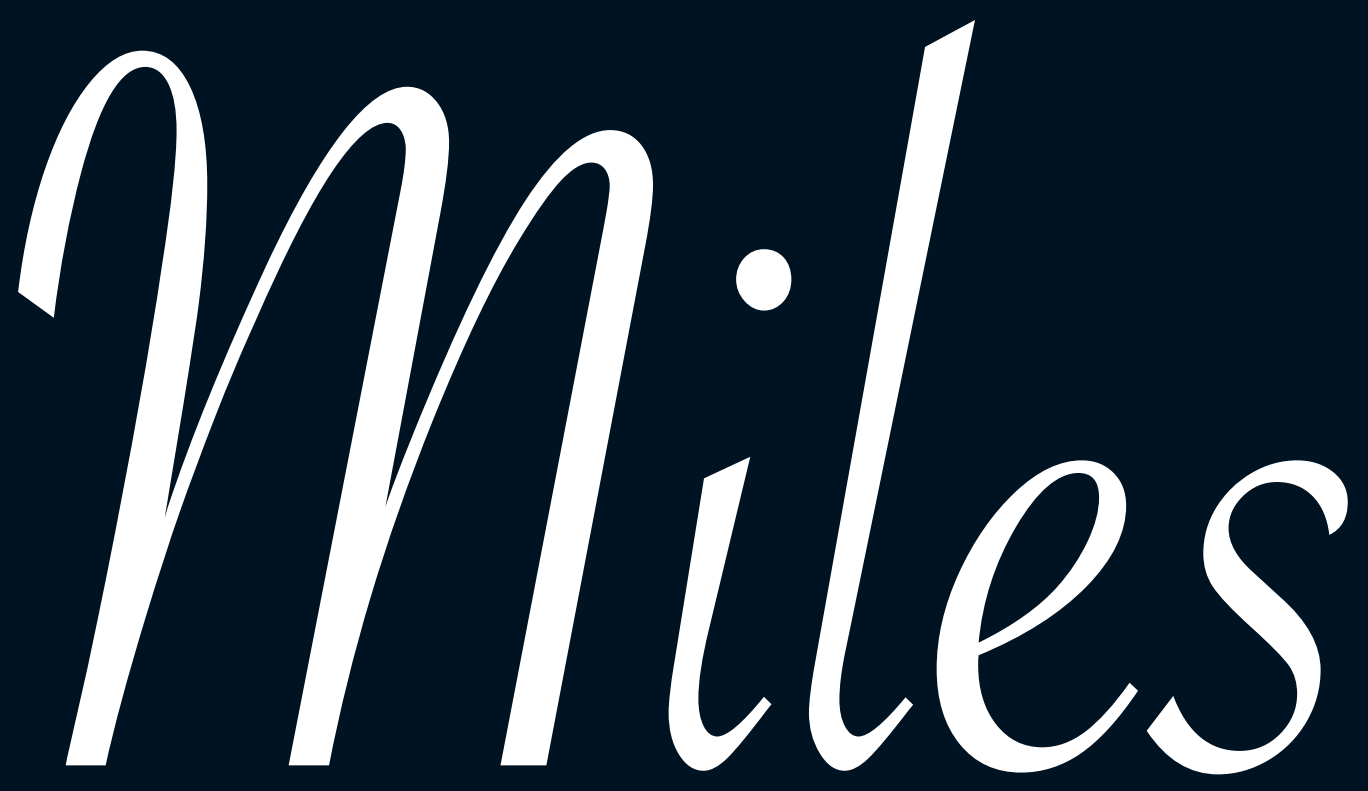




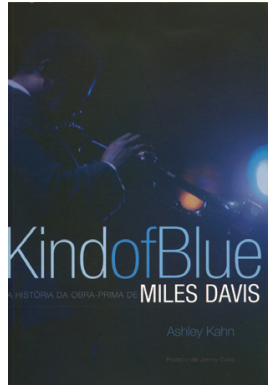

Kind of Blue $-A$ História da Obra-prima de Miles Davis, de Ashley Kahn, tradução de Patrícia de Cia e Marcelo Orozco, São Paulo, Barracuda, $256 \mathrm{p}$

\section{CAIO ÁVILA}

é produtor e apresentador do programa Blues Power da Rádio USP FM. m iles Dewey Davis III nasceu em 26 de maio de 1926 em Alton, no estado de Illinois, Estados Unidos. Seu pai foi um dentista bem-sucedido em Saint Louis e sua mãe, Cleo, uma hábil pianista que tinha o sonho de ver seu filho como um grande violinista. No entanto, aos 13 anos, Miles ganhou de seu pai um trompete. A partir desse instante seu destino estava traçado. Aos 15 anos já tocava com Eddie Randall e estudava com Elwood Buchanan, que lhe ensinou a importância de tocar sem o vibrato, o que acabou se tornando uma das marcas registradas do som intimista de Davis. Em 1944, ficou fascinado com o som bebop de Charlie Parker e Dizzy Gillespie, que visitaram Saint Louis acompanhando o cantor Billy Eckstine. Em 1945, quando terminou seus estudos regulares, mudou-se para Nova York sob o pretexto de estudar na Julliard School of Music. No entanto, suas intenções eram outras: desejava estar ao lado de seus heróis, Charlie e Dizzy. Tempos depois, tornou-se trompetista da banda de Parker, permanecendo com ele durante três anos.

De 1948 a 1950 continuou no bebop trabalhando ao lado do arranjador Gil Evans. De forma paralela, em 1949, Miles começou a trabalhar o seu próprio som, dando origem ao que se denominou cool jazz.
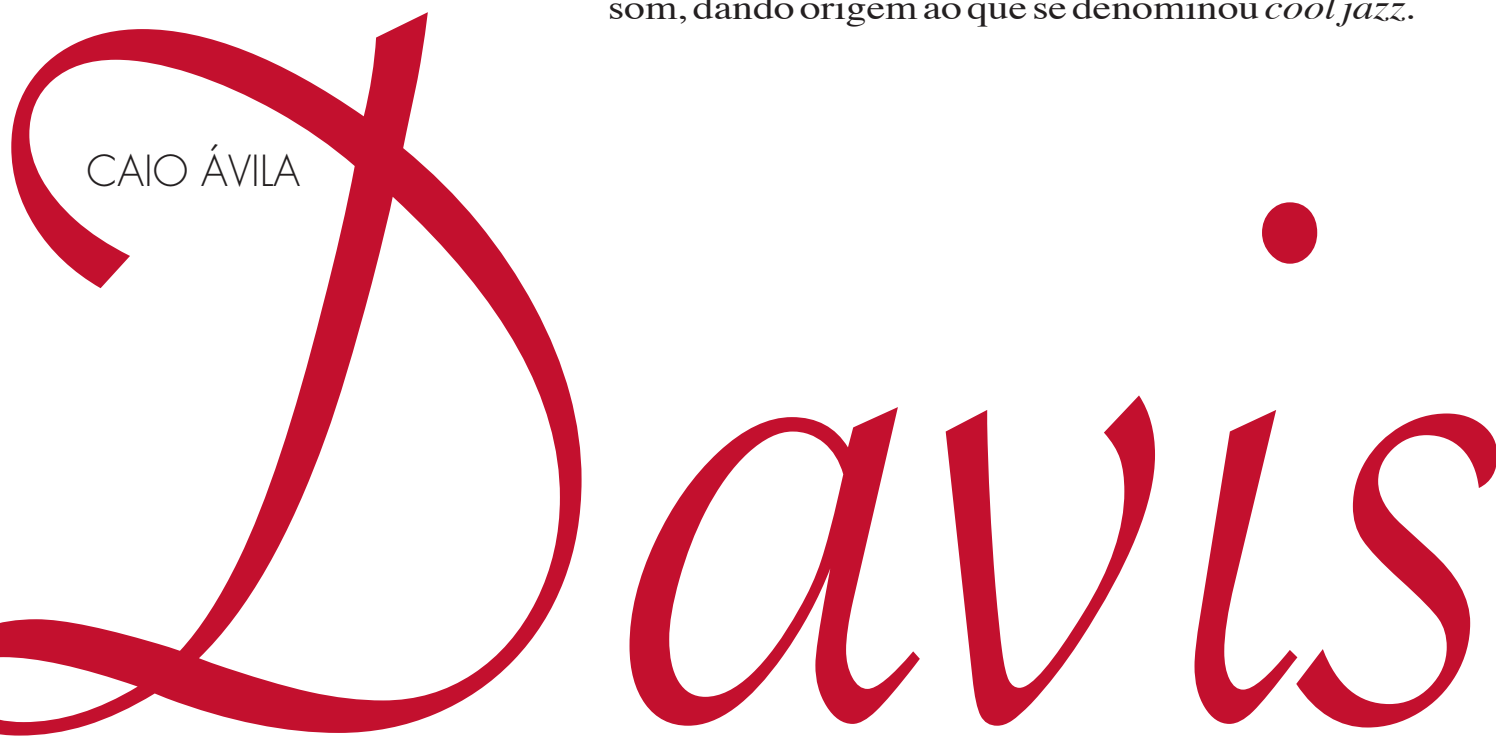


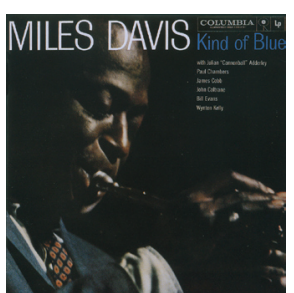

Capa do disco Kind of Blue, de Miles Davis
No início dos anos 50, convivendo com usuários de drogas pesadas nos clubes de jazz de Nova York, tornou-se um feroz dependente de heroína. Em 1954, retornou a Saint Louis e, com a ajuda de seu pai, abandonou o vício, trancando-se por vários dias dentro de um quarto, passando pelo inferno da síndrome de abstinência, também conhecida como cold turkey.

A partir de 1956 passa a liderar um quinteto (às vezes sexteto) que marcou a história do jazz. Nessa época, o sax-tenorista John Coltrane já participava desses trabalhos. Miles gravou uma série de discos com músicos de renome (tais como Sonny Rollins e Milt Jackson) pelo selo chamado Prestige. Assinou posteriormente um contrato com a gravadora Columbia, subsidiária da Sony, mas ele ainda precisava gravar quatro discos pela Prestige antes de iniciar os trabalhos com o novo selo. Sua ansiedade em gravar pela Columbia era tanta que registrou todos os discos faltantes em apenas dois dias, sem necessidade de regravações. Seu primeiro trabalho de impacto pela nova gravadora foi o álbum Milestones. Na primavera de 1959, gravou, pela Columbia, Kind of Blue, a sua obra-prima sobre a qual falaremos substancialmente mais adiante. Depois, em 1960, voltou a gravar com Gil Evans, o que resultou no álbum Sketches of Spain. Em meados dos anos 60 formou outra banda, um sexteto, do qual participavam o pianista Herbie Hancock e o baixista Ron Carter, entre outros. Em 1969, dez anos após Kind of Blue, renovou mais uma vez a linguagem musical misturando o jazz com o rock no álbum duplo Bitches Brew, que contou com a participação de outros brilhantes músicos, a exemplo de Chick Corea, Jack DeJohnette e John McLaughin. Dizem que, nessa época, Miles e Jimmy Hendrix haviam combinado de gravar algo juntos, mas, infelizmente, o guitarrista faleceu pouco tempo depois. Nos anos 70 e 80 seguiu inovando acrescentando batidas negras ao som de seu trompete. Faleceu em 28 de setembro de 1991, deixando um legado musical extraordinário para a humanidade.

Miles Davis, assim como Duke Ellington, sempre incorporou elementos de outros instrumentistas à sua própria música. Com o pianista Thelonious Monk aprendeu que o silêncio era um elemento importantíssimo na música, e que o menos poderia ser mais.

O som do trompete de Miles é único, macio, mas intenso, econômico, porém profundo, repleto de ternura. A renovação da linguagem foi a característica mais importante de sua arte. Foi o criador do cool jazz, modal jazz e fusion jazz.

Miles tinha uma personalidade contraditória. Era inseguro e dentro dele havia um profundo sentimento de raiva. Conta a história que uma vez estava na frente da casa de jazz. Birdland, em Nova York, durante o intervalo de uma apresentação, quando um policial branco o mandou circular e sair de frente do lugar. Miles se negou a obedecer à ordem, alegando que trabalhava no local como músico contratado. Foi preso e espancado com um cassetete até sangrar. Miles não se dava bem com seus fãs e, freqüentemente, se desentendia com donos de boate. Sua vida privada também era bastante conturbada, principalmente por ser um sujeito muito ciumento e possessivo.

Miles Davis gravou discos conceituais e revolucionários. Mas, para o mundo do jazz, Kind of Blue é o trabalho mais importante e profundo de toda a sua carreira. Apesar de ter sido gravado em 1959, o disco continua atual e influente, tendo alcançado a proeza de ser o disco de jazz mais vendido de todos os tempos.

Miles e seu sexteto composto pelo saxofonista tenor John Coltrane, o saxofonista alto Cannonball Aderley, os pianistas Bill Evans e Wynton Kelly, o baixista Paul Chambers e o baterista Jimmy Cobb, foram para a Columbia na 30th Street de Nova York, uma antiga igreja transformada em estúdio, e realizaram duas sessões de gravação, a primeira no dia 2 de março de 1959 e a segunda no dia 24 de abril do mesmo ano. Na primeira sessão, Miles e sua competentíssima banda gravaram os temas "So What", "Freddie Freeloader" e "Blue in Green", o lado um do disco de vinil. Na segunda sessão, foram gravadas 


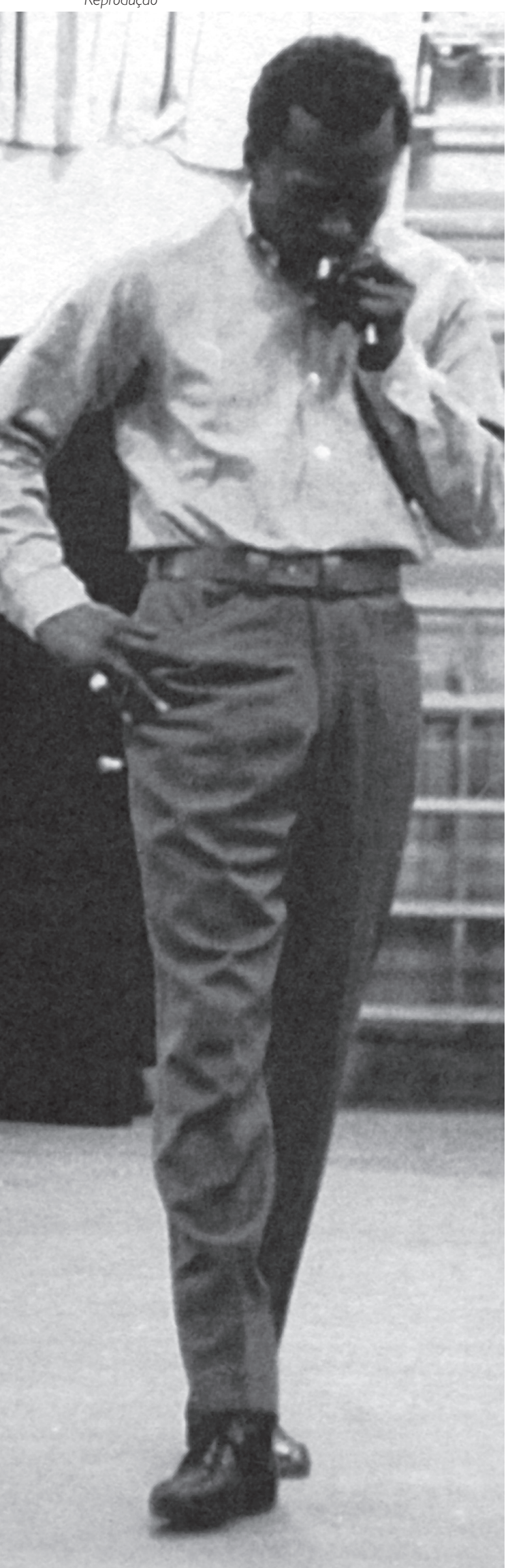

as canções do lado dois, "All Blues" e "Flamenco Sketches”. O disco foi oficialmente lançado em 17 de agosto de 1959. Todas as canções do álbum foram creditadas a Miles, mas estudiosos afirmam que Bill Evans, o único branco do sexteto, escreveu parte dos temas, especialmente "Blue in Green".

Miles, aos 33 anos e com seu estilo econômico, estava com a bala na agulha na época. O bebop e o hard bop, estilos que possuíam complicadas progressões de acordes, já não faziam a cabeça do trompetista. A idéia era trabalhar com escalas ou modos simples, dando prioridade às melodias. Em 1958, essa tendência já aparecia no disco Milestones. Miles Davis havia sofrido forte influência do pianista George Russell, que implementara essa idéia de trabalhar com os modos musicais. Kind of Blue foi o ápice desse movimento. Miles queria algo espontâneo de seus músicos. Nenhum deles sabia ao certo o que iria acontecer durante as sessões, havia apenas uma noção básica, como registrou Bill Evans na contracapa do famoso álbum:

"Miles concebeu esses esquemas apenas algumas horas antes das sessões de gravação, e chegou com esboços que indicavam ao grupo o que deveria ser tocado. Portanto, nestas execuções você irá escutar algo que está próximo da pura espontaneidade. O grupo nunca havia tocado estas peças antes da gravação, e creio que, sem exceção, a primeira interpretação completa de cada uma foi tomada com um take".

Um dos segredos acerca do brilhantismo do álbum é o time arregimentado. Miles aprendera com Charlie Parker que, para se fazer um bom disco, era preciso contar com os melhores músicos. O outro segredo é o clima descontraído das sessões de gravação que deixou o sexteto completamente à vontade para improvisar e ultrapassar barreiras. Mas o grande segredo do álbum, a meu ver, é que se trata de um trabalho acessível, gostoso de se ouvir, até mesmo sensual, ao mesmo tempo simples e profundo, talvez a trilha sonora perfeita para uma noite de amor.

Nesta página

e na seguinte, o músico Miles

Davis 
O disco foi gravado no final dos anos 50. O Sputnik já estava no espaço, a Guerra Fria fervia e o Muro de Berlim apareceria dois anos depois. Nessa época pairava uma grande incerteza na música americana. O jazz estava saturado com os virtuosismos do bebop e não havia uma clara direção para o estilo. O rock'n roll, por sua vez, passava por um período de decadência, sem inspiração, deixando sua origem revolucionária de lado para produzir uma baboseira sentimental comercial. O blues continuava underground, restrito a certas comunidades, principalmente àquelas localizadas na região de Chicago. Kind of Blue foi criado durante esse período, na fase final da geração dos Baby Boomers, e inovou o jazz com sua simplicidade e profundidade.

Neste ano de 2007, foi publicado no Brasil o livro Kind of Blue - A História da Obra-Prima de Miles Davis, escrito por Ashley Kahn, americano, jornalista, professor e produtor de rádio, radicado em Nova Jersey, fã incondicional de Kind of Blue.

O livro começa com o prefácio do baterista Jimmy Cobb. Ele conta que ficou surpreso e lisonjeado pelo convite feito pelo autor e, sobre o disco, recorda que acordou bem cedo naquele dia de primavera de março de 1959 e que estava meio agitado porque teria uma gravação com Miles Davis. Foi até o estúdio da gravadora Columbia na 30th Street, levando a própria bateria. Montou o seu set e ficou esperando o pessoal chegar para ver o que iriam fazer. Quando todos já estavam lá, começaram a tocar os temas trazidos por Miles e, quando acertaram o ponto, segundo Cobb, “o som ficou realmente bonito e suave, sem nenhum esforço, não havia tensão, tudo bem relaxado".

Na introdução, o autor narra a sua visita, numa manhã de dezembro de 1999, aos estúdios da Sony, onde pôde ouvir as fitas originais de Kind of Blue, com as vozes dos músicos nos intervalos das sessões e as passagens de som. Conta também que, quando a fita começou a passar pelo cabeçote do gravador, alguns engenheiros de som da Sony, que ficaram sabendo que as masters seriam reproduzidas naquele dia, apareceram e se acomodaram pelos cantos

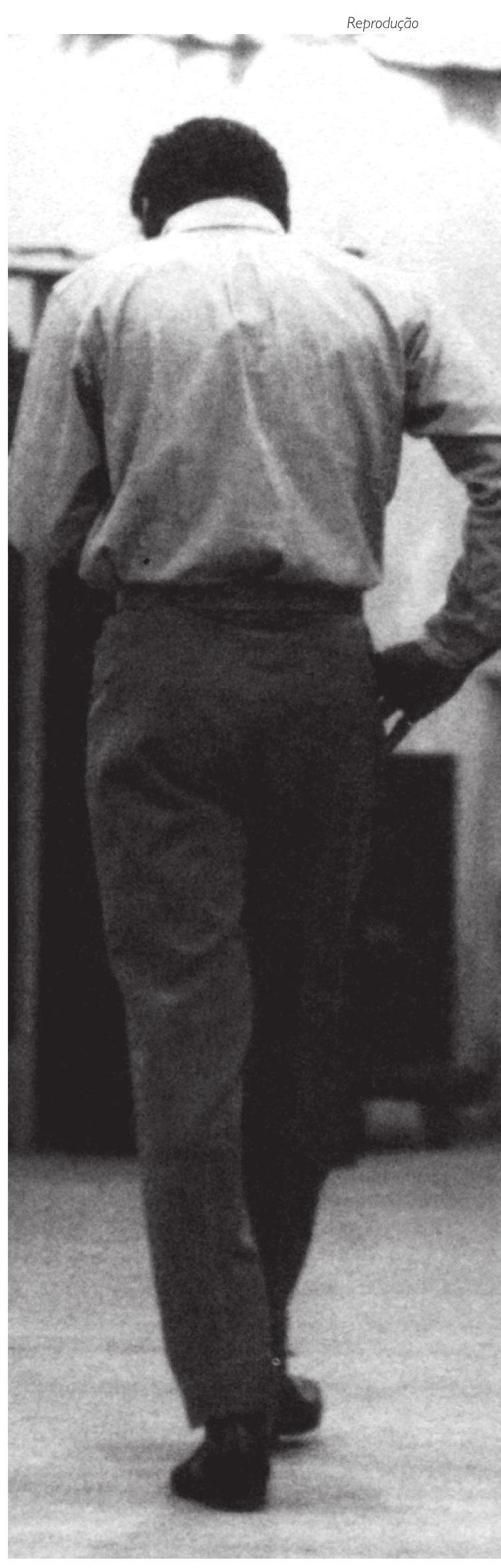


para ouvi-las. Isso demonstra o interesse que o álbum ainda desperta nas pessoas.

Ao longo do livro o autor conta detalhes da trajetória de Miles Davis e como ele desenvolveu o seu estilo econômico.

As duas sessões de gravação de Kind of Blue são o ponto central do livro. Ashley Kahn esmiúça faixa por faixa do disco. Começa por "Freddie Freeloader", a segunda faixa do lado um do disco, que tem a estrutura mais próxima do blues tradicional. São 12 compassos que formam um chorus que se repete inúmeras vezes. "Freddie Freeloader" traduzido para o português significa "Freddie, o Parasita". Trata-se de um blues instrumental extremamente melódico, no qual Miles presta uma “homenagem" a Fred Tolbert, um maluco inofensivo que grudou no trompetista e que lhe servia de garoto de recados. Depois, o autor descreve a gravação de "So What", a faixa mais conhecida que abre Kind of Blue e tem como característica seu "prelúdio divagante, deslocado no tempo em relação à estrutura predominante da música, atmosférico e carregado de expectativa". Na seqüência, há a descrição da gravação da faixa "Blue in Green", da qual Bill Evans reivindicou autoria. Kahn a descreve como a "discreta miniatura em meio a um álbum de meditações mais extensas, com cinco minutos e meio de solos calmos e ondulantes sobre um círculo de acordes". "Blue in Green" é a terceira faixa do lado um e a menor do disco. Essas três faixas foram gravadas na primeira sessão realizada em 2 de março de 1959. Depois, o autor descreve as gravações das outras duas faixas que constituem o lado dois de Kind of Blue: "All Blues" e "Flamenco Sketches", gravadas em 22 de abril de 1959. Sobre "All Blues" o autor afirma que ela é totalmente Miles, misturando elementos diferentes. Nessa faixa, o baixista Paul Chambers repete incessantemente um riff, uma das manhas do velho e bom blues. "Flamenco Sketches", por sua vez, é o tema mais modal do álbum, cujo crédito deveria ter sido partilhado entre Miles e Bill Evans. As escalas utilizadas em "Flamenco Sketches" vão do repousante modo jônico ao tenso mixolídio, chegando até o estrangeiro frígio, um tema multicultural com diferentes emoções.

$\mathrm{O}$ autor conta fatos relacionados aos membros do sexteto de Miles e trata também da repercussão e do legado deixado por Kind of Blue. Por fim, vale registrar que há no livro muitas fotos em preto e branco das sessões de gravação, bem como outras fotos da carreira de Miles. Kind of Blue - A História da Obra-Prima de Miles Davis, escrito por Ashley Kahn, é um trabalho minucioso, fruto de uma profunda pesquisa, redigido de maneira objetiva e direta, que agradará tanto o leigo quanto o entendido em jazz. A minha sugestão: leia o livro ouvindo Kind of Blue. Você, novato ou expert, não se arrependerá. 